\title{
Nanoscale Metal-Organic Frameworks as Potential Multimodal Contrast Enhancing Agents
}

\author{
William J. Rieter ${ }^{\dagger}$, Kathryn M. L. Taylor ${ }^{\dagger}$, Hongyu An ${ }^{\ddagger}$, Weili Lin $\ddagger$, and Wenbin $\operatorname{Lin}^{\dagger}$ \\ $\dagger$ Department of Chemistry, University of North Carolina, Chapel Hill, NC 27599 \\ \$Department of Radiology, University of North Carolina, Chapel Hill, NC 27599
}

Nanomaterials have been actively pursued as new molecular probes for biomedical imaging.

${ }^{1}$ The vast majority of nano-sized imaging probes are based on purely inorganic materials such as quantum dots, ${ }^{2}$ superparamagnetic metal oxides, ${ }^{3}$ and gold nanoparticles or nanoshells. ${ }^{4}$ Metal-organic frameworks (MOFs) are a new class of hybrid materials built from metal ions with well-defined coordination geometry and organic bridging ligands which have already shown promise in a number of applications including catalysis, ${ }^{5}$ nonlinear optics, 6 and gas storage. ${ }^{7}$ In contrast to inorganic materials, the compositions and structures of MOFs are innumerable owing to the choice of a vast range of metal ions and organic linkers. We thus envision that new multimodal imaging probes can be designed by incorporating suitable metal ions and organic moieties into nanoscale metal-organic frameworks (NMOFs).

Although there is an extensive literature on the synthesis and characterization of bulk MOF materials, few reports have appeared on NMOFs. ${ }^{8}$ Wang et al. synthesized submicrometerscale spherical colloids of the Pt(p-phenylenediamine) system by simply mixing the metal and organic components in aqueous solution, ${ }^{8 \mathrm{a}}$ whereas Mirkin et al. prepared spherical particles of a zinc MOF via precipitation induced by a poor solvent. ${ }^{8 \mathrm{~b}}$ These methods are however not applicable to other metal-ligand combinations, and the amorphous nature of the resulting colloid particles prohibits a detailed understanding of these systems. Herein we wish to report a general water-in-oil microemulsion-based methodology for the synthesis of NMOFs and their preliminary evaluation as multimodal imaging probes.

$\mathrm{Gd}(\mathrm{BDC})_{1.5}\left(\mathrm{H}_{2} \mathrm{O}\right)_{2}(\mathbf{1})$ nanorods (where $\mathrm{BDC}$ is 1,4-benzenedicarboxylate) were prepared by stirring an optically transparent microemulsion of $\mathrm{GdCl}_{3}$ and bis(methylammonium)benzene-1,4-dicarboxylate (in a 2:3 molar ratio) in the cationic cetyltrimethylammonium bromide (CTAB)/isooctane/1-hexanol/water system for $2 \mathrm{~h}$. The nanorods of 1 were isolated in $84 \%$ yield by centrifugation and washing with ethanol and water. Scanning electron micrographic (SEM) images of $\mathbf{1}$ demonstrated the formation of nanorods of fairly uniform shape and size (Fig 1). The morphologies and sizes of the nanorods were influenced by the $w$ value (defined as the water/surfactant molar ratio) of the microemulsion systems. For example, nanorods of 1 of 100 to $125 \mathrm{~nm}$ in length by $40 \mathrm{~nm}$ in diameter were obtained with $w=5$ and a $\mathrm{Gd}^{3+}$ concentration of $50 \mathrm{mM}$. As the $w$ value was increased to 10 , nanorods of $\mathbf{1}$ one to two $\mu \mathrm{m}$ in length and $\sim 100 \mathrm{~nm}$ in diameter were obtained under otherwise identical conditions. We have carried out numerous syntheses and have observed very consistent morphologies and sizes for nanorods of $\mathbf{1}$ under identical conditions. The particle size of $\mathbf{1}$ was also affected by the reactant concentration and the reactant ratio. A decrease in the

E-mail: wlin@unc.edu.

Supporting Information Available: Experimental procedures and 9 figures. This material is available free of charge via the Internet at http://pubs.acs.org. 
concentration of reactants or a deviation of the metal to ligand molar ratio from 2:3 typically resulted in a decrease of the particle size. Powder X-ray diffraction (PXRD) studies showed that the nanorods of $\mathbf{1}$ were crystalline and had the same diffraction pattern as the bulk phase of $\mathrm{Tb}(\mathrm{BDC})_{1.5}\left(\mathrm{H}_{2} \mathrm{O}\right)_{2} .{ }^{9}$ The composition of 1 was further supported by thermogravimetric analysis which showed that 1 lost the two coordinated water molecules in the 125 to $140{ }^{\circ} \mathrm{C}$ range.

To probe the generality of NMOF synthesis in reverse microemulsions, we have carried out reactions of $\mathrm{GdCl}_{3}$ and tri(methylammonium)benzene-1,2,4-tricarboxylate (1,2,4-BTC) in the CTAB/isooctane/1-hexanol/water microemulsion system. As shown in Fig 2, irregularlyshaped, crystalline nanoplates of $\left[\mathrm{Gd}(1,2,4-\mathrm{BTC})\left(\mathrm{H}_{2} \mathrm{O}\right)_{3}\right] \cdot \mathrm{H}_{2} \mathrm{O}, 2$, with a diameter of $\sim 100 \mathrm{~nm}$ and an average thickness of $35 \mathrm{~nm}$ were successfully synthesized with a $w$ value of 15 . The identity and phase purity of the nanoplates of $\mathbf{2}$ were also confirmed by PXRD and TGA results (supporting info). ${ }^{10}$ Although reverse microemulsions have been successfully used for the synthesis of a range of nanomaterials including organic polymers, semiconductors, and metal oxides, these are the first examples of NMOF syntheses in reverse microemulsions.

The presence of the $\mathrm{Gd}^{3+}$ centers in $\mathbf{1}$ and $\mathbf{2}$ has prompted us to examine their utility as nanoscale contrast agents for magnetic resonance imaging (MRI). MRI is a powerful noninvasive medical diagnostic technique that can differentiate normal tissues from diseased tissues based on their varied NMR water proton signals arising from different water densities and/or nuclear relaxation rates. ${ }^{11}$ Complexes of highly paramagnetic metal ions such as $\mathrm{Gd}^{3+}$ are often administered to enhance the image contrast by increasing water proton relaxation rates. Currently available metal chelate-based contrast agents however exhibit modest longitudinal (R1) relaxivities and large quantities (several grams per patient) must be administered to provide adequate MR contrast. We rationalize that 1 and 2 NMOFs contain a large number of $\mathrm{Gd}^{3+}$ centers and would therefore give very large relaxivities on a per particle basis. When conjugated to targeting moieties, such nanomaterials can be effective site-specific MR contrast agents owing to their large metal payload.

Relaxivity data obtained with suspensions of 1 in water containing $0.1 \%$ xanthan gum showed that nanorods of 1 of $\sim 100 \mathrm{~nm}$ in length and $\sim 40 \mathrm{~nm}$ in diameter (with $\sim 4.5 \times 10^{5} \mathrm{Gd}^{3+} /$ nanorod) had an $\mathrm{R} 1$ value of $35.8 \mathrm{~s}^{-1}$ per $\mathrm{mM}$ of $\mathrm{Gd}^{3+}$ and $\sim 1.6 \times 10^{7} \mathrm{~s}^{-1}$ per $\mathrm{mM}$ of nanorod. 1 also exhibited a transverse relaxivity (R2) of $55.6 \mathrm{~s}^{-1}$ per $\mathrm{mM} \mathrm{Gd}^{3+}$ and $\sim 2.5 \times 10^{7} \mathrm{~s}^{-1}$ per $\mathrm{mM}$ of nanorod. This level of $\mathrm{R} 1$ relaxivity is unprecedented and at least an order of magnitude higher than those of $\mathrm{Gd}^{3+}$-containing liposomes which have been shown to be effective target-specific MR contrast agents for cancer and cardiovascular disease. ${ }^{12}$ Nanorods of 1 of $\sim 400 \mathrm{~nm}$ in length by $\sim 70 \mathrm{~nm}$ in diameter (with $\sim 7.4 \times 10^{6} \mathrm{Gd}^{3+} /$ nanorod) had an $\mathrm{R} 1$ value of $26.9 \mathrm{~s}^{-1}$ per $\mathrm{mM} \mathrm{Gd}^{3+}$ and $\sim 2.0 \times 10^{8} \mathrm{~s}^{-1}$ per mM nanorod as well as an $\mathrm{R} 2$ of $49.1 \mathrm{~s}^{-1}$ per $\mathrm{mM} \mathrm{Gd}^{3+}$ and $\sim 3.6 \times 10^{8} \mathrm{~s}^{-1}$ per $\mathrm{mM}$ of nanorod. A further increase in particle size to $\sim 1 \mu \mathrm{m}$ in length and $\sim 100 \mathrm{~nm}$ in diameter $\left(\sim 5.6 \times 10^{7} \mathrm{Gd}^{3+}\right.$ /nanorod) resulted in an $\mathrm{R} 1$ of $20.1 \mathrm{~s}^{-1}$ per $\mathrm{mM} \mathrm{Gd}^{3+}$ and $\sim 1.1 \times 10^{9} \mathrm{~s}^{-1}$ per $\mathrm{mM}$ nanorod and an $\mathrm{R} 2$ of $45.7 \mathrm{~s}^{-1}$ per $\mathrm{mM} \mathrm{Gd} \mathrm{C}^{3+}$ and $\sim 2.6 \times 10^{9} \mathrm{~s}^{-1}$ per $\mathrm{mM}$ of nanorod. The inverse size dependence of per $\mathrm{mM} \mathrm{Gd}^{3+}$ relaxivity observed for 1 is consistent with the decreasing surface to volume ratio for the larger nanorods. We believe that the $\mathrm{Gd}^{3+}$ centers at or near the surface are primarily responsible for the observed relaxivities. We also measured the relaxivities of nanoplates of 2 of a diameter of $\sim 100 \mathrm{~nm}$ and an average thickness of $35 \mathrm{~nm}$ which exhibited an R1 of $13.0 \mathrm{~s}^{-1}$ per $\mathrm{mM} \mathrm{Gd}^{3+}$ and $\sim 3.25 \times 10^{7} \mathrm{~s}^{-1}$ per $\mathrm{mM}$ nanoplate (with $\sim 2.5 \times 10^{6} \mathrm{Gd}^{3+} /$ nanoplate) and an $\mathrm{R} 2$ of $29.4 \mathrm{~s}^{-1}$ per $\mathrm{mM} \mathrm{Gd}^{3+}$ and $\sim 7.35 \times 10^{7} \mathrm{~s}^{-1}$ per $\mathrm{mM}$ of nanoplate.

As shown in Fig 3c, nanorods of $\mathbf{1}$ are much more efficient in enhancing the water signals in T1-weighted images than clinically used OmniScan. Interestingly however, very significant signal reduction was caused by nanorods of $\mathbf{1}$ in T2-weigthed images (supporting information) 
when a spin-echo pulse sequence was used. The very high $\mathrm{R} 1$ and $\mathrm{R} 2$ relaxivities exhibited by 1 and 2 thus allow their use as both T1- and T2-contrast agents depending on the MR pulse sequence employed.

We have also successfully synthesized luminescent nanorods of 1 by using $\mathrm{Eu}^{3+}$ or $\mathrm{Tb}^{3+}$ dopants. By mixing in $5 \mathrm{~mol} \%$ of $\mathrm{EuNO}_{3}$ or $\mathrm{TbNO}_{3}$ during the syntheses, nanorods of similar sizes and morphologies to $\mathbf{1}$ were obtained and had the compositions of $\mathrm{Gd}_{0.95}(\mathrm{BDC})_{1.5}\left(\mathrm{H}_{2} \mathrm{O}\right)_{2}: \mathrm{Eu}_{0.05}(\mathbf{1 a})$ and $\mathrm{Gd}_{0.95}(\mathrm{BDC})_{1.5}\left(\mathrm{H}_{2} \mathrm{O}\right)_{2}: \mathrm{Tb}_{0.05}(\mathbf{1 b})$. Ethanol dispersions of these doped nanorods are highly luminescent upon UV excitation with characteristic red and green luminescence from $\mathrm{Eu}^{3+}$ and $\mathrm{Tb}^{3+}$, respectively (Fig 3d). These results suggest that NMOFs such as $\mathbf{1}$ can be used as potential contrast agents for multimodal imaging.

In summary, we have developed a general reverse microemulsion-based methodology for the synthesis of NMOFs. These NMOFs exhibit large R1 and R2 relaxivities on a per $\mathrm{mM}$ of $\mathrm{Gd}^{3+}$ basis and extraordinarily large $\mathrm{R} 1$ and $\mathrm{R} 2$ relaxivities on a per $\mathrm{mM}$ of nanoparticle basis. Doping of luminescent lanthanide ions was also demonstrated. Molecular targeting of such NMOFs to biomarkers that are associated with certain diseased cells should be feasible to potentially lead to a new class of target-specific multimodal imaging contrast agents.

\section{Supplementary Material}

Refer to Web version on PubMed Central for supplementary material.

\section{ACKNOWLEDGMENT}

We acknowledge financial support from NSF (CHE-0512495) and NIH grants (U54-CA119343-01 and P20 RR020764-01). WJR thanks NSF for a graduate fellowship and WL is a Camille Dreyfus Teacher-Scholar.

\section{References}

1. a Cheng MM-C, Cuda G, Bunimovich YL, Gaspari M, Heath JR, Hill HD, Mirkin CA, Nijdam AJ, Terracciano R, Thundat T, Ferrari M. Curr Opin. Chem. Biol 2006;10:11. [PubMed: 16418011] b Toublan FJ-J, Boppart S, Suslick KS. J. Am. Chem. Soc 2006;128:3472. [PubMed: 16536492]

2. a Alivisatos AP. Nat. Biotechnol 2004;22:47. [PubMed: 14704706] b Kim S-W, Zimmer JP, Ohnishi S, Tracy JB, Frangioni JV, Bawendi MG. J. Am. Chem. Soc 2005;127:10526. [PubMed: 16045339] c Gao X, Cui Y, Levenson RM, Chung LWK, Nie S. Nat. Biotechnol 2004;22:969. [PubMed: 15258594]

3. Weissleder R, Moore A, Mahmood U, Bhorade R, Benveniste H, Chiocca EA, Basilion JP. Nat. Med 2000;6:351. [PubMed: 10700241]

4. a Chen J, Saeki F, Wiley B, Cang H, Cobb MJ, Li Z-Y, Au L, Zhang H, Kimmey MB, Li X, Xia Y. Nano Lett 2005;5:473. [PubMed: 15755097] b Loo C, Lowery A, Halas N, West J, Drezek R. Nano Lett 2005;4:709. [PubMed: 15826113] c Nam J-M, Thaxton CS, Mirkin CA. Science 2003;301:1884. [PubMed: 14512622]

5. Wu C, Hu A, Zhang L, Lin W. J. Am. Chem. Soc 2005;127:8940. [PubMed: 15969557]

6. Evans OR, Lin W. Acc. Chem. Res 2002;35:511. [PubMed: 12118990]

7. Matsuda R, Kitaura R, Kitagawa S, Kubota Y, Belosludov RV, Kobayashi TC, Sakamoto H, Chiba T, Takata M, Kawazoe Y, Mita Y. Nature 2005;436:238. [PubMed: 16015325]

8. a Sun X, Dong S, Wang E. J. Am. Chem. Soc 2005;127:13102. [PubMed: 16173711] b Oh M; Mirkin CA. Nature 2005;438:651. [PubMed: 16319888]

9. a Bondareva LN, Dvornikova LM, Knyazeva LD. Izvest. Vysshikh Uchebnykh Zavadenii, Khim. i Khimich. Tehknol 1974;17:342. b Reineke TM, Eddaoudi M, Fehr M, Kelley D, Yaghi OM. J. Am. Chem. Soc 1999;121:1651. 
10. PXRD indicates that nanoplates of 2 have the same structure as the known bulk phase. See: Jin Z-S; Duan Z-B; Wei G-C, Ni J-Z. Chinese J. Sruct. Chem 1990;9:69.

11. Toth, É.; Helm, L.; Merbach, AE. The Chemistry of Contrast Agents in Medical Magnetic Resonance Imaging. John Wiley \& Sons; Chichester: 2001. b Caravan P, Ellison JJ, McMurry TJ, Lauffer RB. Chem. Rev 1999;99:2293. [PubMed: 11749483]

12. Morawski AM, Lanza GA, Wickline SA. Curr Opin. Biotechnol 2005;16:89. [PubMed: 15722020] 

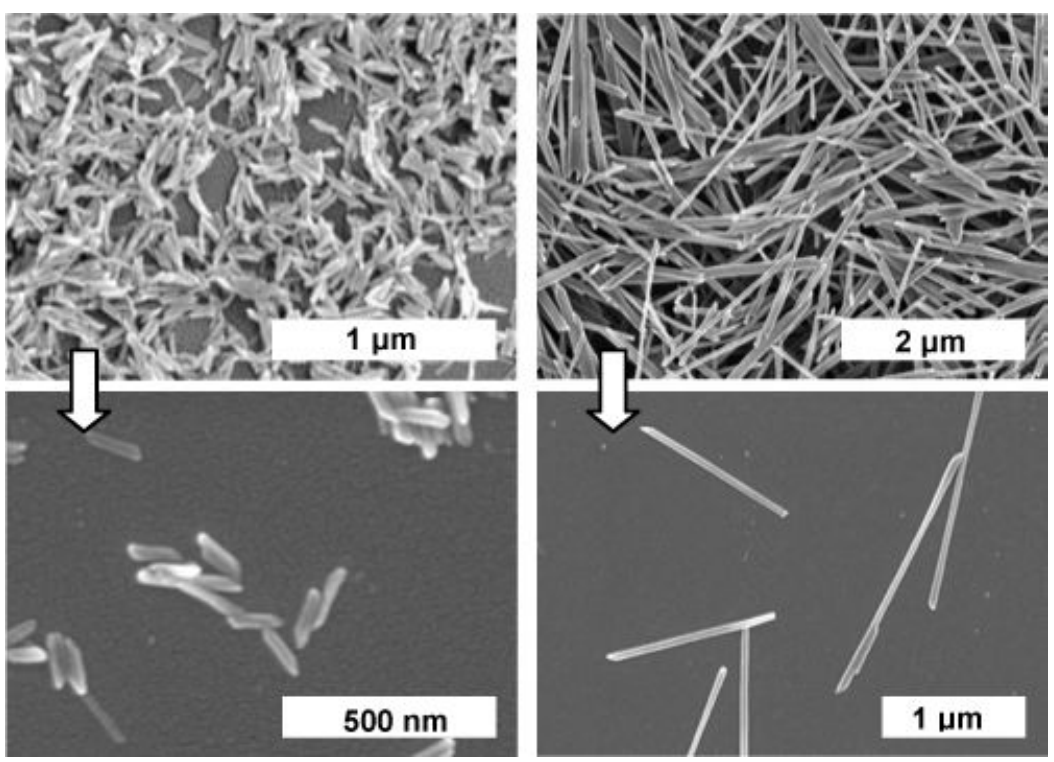

Figure 1.

SEM images of $\mathrm{Gd}(\mathrm{BDC})_{1.5}\left(\mathrm{H}_{2} \mathrm{O}\right)_{2}(\mathbf{1})$ nanorods synthesized with $\mathrm{w}=5$ (left) and $\mathrm{w}=10$ (right). 


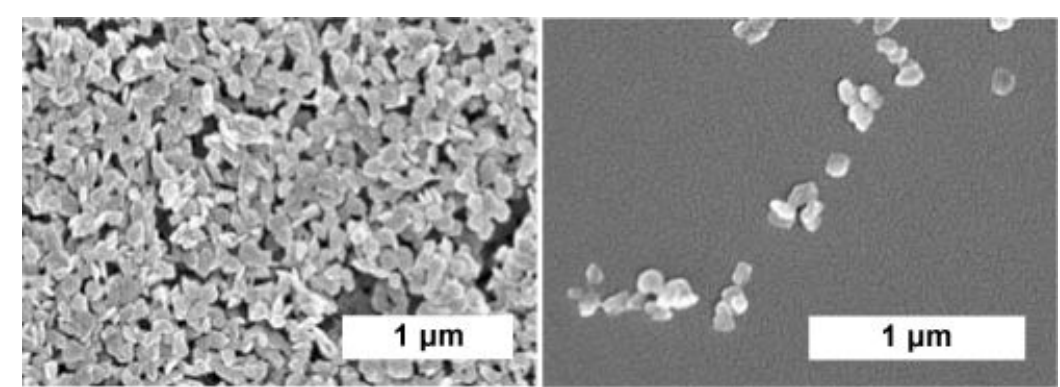

Figure 2.

SEM images of irregularly-shaped, crystalline $\left[\mathrm{Gd}(1,2,4-\mathrm{BTC})\left(\mathrm{H}_{2} \mathrm{O}\right)_{3}\right] \cdot \mathrm{H}_{2} \mathrm{O}(2)$ nanoplates. 

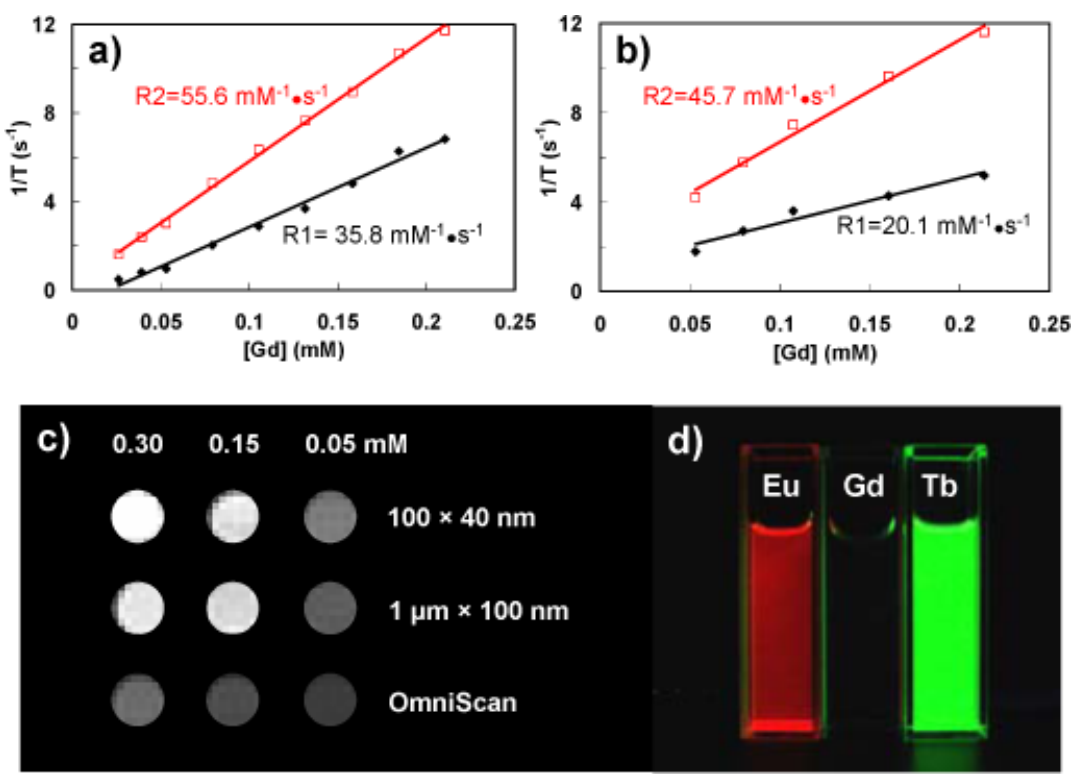

Figure 3.

(a) R1 and R2 relaxivity curves of 1 of $\sim 100 \mathrm{~nm}$ in length by $\sim 40 \mathrm{~nm}$ in diameter. (b) R1 and $\mathrm{R} 2$ relaxivity curves of 1 of $\sim 1 \mu \mathrm{m}$ in length by $\sim 100 \mathrm{~nm}$ in diameter. In comparison, OmniScan gave an R1 of $4.1 \mathrm{mM}^{-1} \bullet \mathrm{s}^{-1}$ under these conditions. (c) T1-weighted MR images of suspensions of 1 in water containing $0.1 \%$ xanthan gum. (d) Luminescence images of ethanolic suspensions of $\mathbf{1}, \mathbf{1 a}\left(\mathbf{1}\right.$ doped with $\left.5 \mathrm{~mol} \% \mathrm{Eu}^{3+}\right)$, and $\mathbf{1 b}\left(\mathbf{1}\right.$ doped with $\left.5 \mathrm{~mol} \% \mathrm{~Tb}^{3+}\right)$. 